\title{
Impact of COVID-19 on FMCG Sector
}

\author{
S. Rajamohan \\ Senior Professor \& Director, Alagappa Institute of Management \\ Alagappa University, Karaikudi, Tamil Nadu, India \\ J. Jenefer \\ Ph.D. Research Scholar, Alagappa Institute of Management \\ Alagappa University, Karaikudi, Tamil Nadu, India \\ D http://orcid.org/0000-0003-0112-629X
}

\section{OPEN ACCESS}

Manuscript ID:

MGT-2021-08043817

Volume: 8

Issue: 4

Month: April

Year: 2021

P-ISSN: 2321-4643

E-ISSN: 2581-9402

Received: 01.02.2021

Accepted: 09.03.2021

Published: 01.04.2021

Citation:

Rajamohan, S., et al.

"Impact of COVID-19 on

FMCG Sector.” Shanlax

International Journal of

Management, vol. 8, no. 4, 2021, pp. 69-74.

DOI:

https://doi.org/10.34293/

management.v8i4.3817

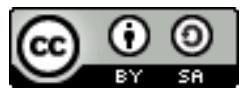

This work is licensed under a Creative Commons Attribution-ShareAlike 4.0 International License.

\section{A. Sathish}

Ph.D. Research Scholar, Alagappa Institute of Management Alagappa University, Karaikudi, Tamil Nadu, India

\begin{abstract}
Coronavirus pandemic shows an unprecedented change globally, and the impact is even higher in emerging economies like India. Fast Moving Consumer Goods (FMCG) is one of the largest sectors in India with varied businesses, including household, personal care, etc., with high demand, consumed frequently, and services are provided for a low cost. This paper is an attempt to study the outbreak of COVID-19 in the FMCG sector. It shows that FMCG is affected uncommonly with many factors like Labours moved to their natives, logistics issues, and changes in the consumer basket like a sudden increase in demand for sanitary products and surged in demand for cosmetics.
\end{abstract}

Keywords: Coronavirus, Pandemic, Outbreak, FMCG, Volatility, Stationarity

\section{Introduction}

The world had seen pandemics like the Spanish flu, Asian flu SARS and many more in the past decades. Pandemic all over the world creates varied impact in terms of socially, economically, and psychologically. The case here is COVID-19 which has locked the world for nearly a year, started from Asia, and it affected most of the countries. A country like India in its developing phase reaction is even higher. Many sectors have gone through severe changes like loss of jobs in the tourism sector due to travel restrictions, and decreased demand for travel has affected the aviation industry. Like most of the sector, Fast Moving Consumer Goods (FMCG) has also faced a sudden change and adversely affected. FMCG is a dynamic sector in the Indian economy with high consumer demand; due to its consumer demand, it is often purchased and consumed rapidly. The growth of the industry is increasing day by day with varied forms. The urban sector is the largest contributor, but in the recent phase, the rural sector contribution is increasing rapidly. In this pandemic recession, it has undergone a drastic stage. The main reasons are lack of labor, operations limiting to production, increased knowledge in health and hygiene, boost the demand for sanitizer, hand wash, tissue, etc., and improved demand for organic goods results in a shift in consumer preference. So there is a surge in the sectors contribution to the GDP; it is necessary to analyze changes in the sector to avoid future complications. When comparing the data with before and after the Covid-19 crisis, the impact is noticeable. This study specifically focused on the impact of Covid-19 on the FMCG sector. 


\section{Review of Literature}

Weare in themiddleofaglobalCovid-19pandemic, which is inflicting two kinds of shocks on countries: a health shock and an economic shock. Given the nature of the disease which is highly contagious, the ways to contain the spread include policy actions such as imposition of social distancing, self-isolation at home, closure of institutions, and public facilities, restrictions on mobility and even lock-down of an entire country. These actions can potentially lead to dire consequences for economies around the world. In other words, effective containment of the disease requires the economy of a country to stop its normal functioning. This has triggered fears of a deep and prolonged global recession. On April 9, the chief of International Monetary Fund, Kristalina Georgieva said that the year 2020 could see the worst global economic fallout since the Great Depression in the 1930 s, with over 170 countries likely to experience negative per capita GDP growth due to the raging coronavirus pandemic.

Jakhotiya, Girish, (2020). The Indian economy is undergoing significant field of growth in FMCG sector with diverse businesses, including food, beverages, grains, cosmetics etc. The paper studies the impact of coronavirus pandemic on FMCG sector in India and the impact on consumer behaviour in India. The paper found that the FMCG sector is highly affected by coronavirus pandemic and employment is affected in India as labourers have moved to their native place due to coronavirus pandemic. The companies' responses to this issue include the introduction of protection procedures, sanitation and sanitization methods, an updated sourcing policy, the incorporation of new vendors, the streamlining of their product portfolio, a more responsive evaluation of supply chain resilience, an analysis of disaster or emergency management plans. In this way FMCG sector can cope with the coronavirus pandemic.

Yogesh D Mahajan (2020) it is a descriptive paper. He pointed out that FMCG sector is highly affected due to COVID-19 and also changes in consumer preference. There is a shift in which certain sector will accelerate and others slow down. Those companies which is able to respond to the evolving dynamics of demand and shows a resilient attitude can overcome pandemic. Philipp Carlsson Szlezak, et al (2020) Having largely ignored Covid-19 as it spread across China, global financial markets reacted strongly last week when the virus spread to Europe and the Middle East, stoking fears of a global pandemic. Since then, Covid-19 risks have been priced so aggressively across various asset classes that some fear a recession in the global economy may be a foregone conclusion.

S. Rajamohan, et al (2020) The COVID-19 in India made an adverse impact in automobile sector during the study period. The sudden fall of stock values affect the industry manufacturing process and it has been influenced the stock market for a period and it may recover soon with optimum potential. Amit Joshi, et al (2020) exclaimed the impact of covid19 and the ways in which the various sectors in the country affected, also suggested appropriate measures to control the negative impacts. S.Mahendra Dev (2020) pointed out the potential impact of covid-19 in various economic segments and examined policies announced by the central government and measures taken by Reserve bank of India and also suggested for certain sectors

\section{Design of the Study \\ Objectives of the Study}

- To examine the stationarity of FMCG sector index during pre and post COVID-19.

- To measure the influence of COVID-19 in the price movements of FMCG sector.

- To analyse the volatility index price of FMCG sector during prior and ahead COVID-19.

\section{Hypothesis}

- H0: The Index price return of FMCG sector is not volatile.

- H0: The COVID-19 does not influence the index price returns of FMCG sector.

\section{Methodology of the Study}

This study is of both descriptive and analytical in nature and discusses the positive and negative impact of COVID-19 on FMCG sector.

Sources of Data: The study uses secondary data for the analysis of FMCG sector, the data is taken from NSE. To examine the sources were collected from magazines, journals, newspapers etc. 
Period of Data: For analysing the impact of COVID-19 on FMCG sector, the data collected for pre covid-19 from January 2019 to December 2019 and for post covid-19 from January 2020 to December 2020.

\section{Data Analysis and Interpretation}

The data collected are analysed through respective statistical tools like Relative Strength Index (RSI), Augmented Dickey Fuller Test (ADF) and GARCH $(1,1)$ Model.

Measuring the Speed and Changes of Price Movements by using Relative Strength Index

The Relative Strength Index (RSI) was introduced by Welles Wilder in June 1978, it is one of the extensively used technical indicators used in the analysis of financial markets. Momentum oscillators calculates the speed and price movement of the security, RSI compares the average gain and average losses of the security. The standard has to use 14 periods to calculate the RSI initial value.

The formula for RSI is

$\mathrm{RSI}=100-(100 / 1+\mathrm{RS})$

$\mathrm{RS}=$ Average gain per day/ Average loss per day The change is calculated by the differences in the current and previous prices. Upward trend is calculated by increasing in change and downward is calculated by decreasing in changes, later the average upward and average downward is calculated for 14 days before each and every day respectively.

Price Movements of FMCG Sector during the Pre COVID-19 Period

Table 1: Average Value of RSI in Pre COVID-19 in FMCG Sector

\begin{tabular}{|c|c|c|c|c|c|c|}
\hline \multirow{2}{*}{$\begin{array}{c}\text { Average } \\
\text { Value }\end{array}$} & Upward & Downward & Average Up & Average Down & Relative Strength & RSI \\
\cline { 2 - 7 } & 180.5926724 & 165.8257813 & 176.1458123 & 167.0203957 & 1.170451746 & 49.24691751 \\
\hline
\end{tabular}

Source: Collected from www.nseindia.com and computed

In RSI the value ranges from 0 to 100 , the value of 70 or more than is overbought condition if reading is 30 or less than, it is oversold condition, the condition prevailed in pre-covid RSI average (49.24691751) i.e average performance of share, it clearly indicates share is neither overbought nor oversold of FMCG sector in pre-covid.

Table 2: Average Value of RSI in Post COVID-19 in FMCG Sector

\begin{tabular}{|c|c|c|c|c|c|c|}
\hline $\begin{array}{c}\text { Average } \\
\text { Value }\end{array}$ & Upward & Downward & Average Up & Average Down & Relative Strength & RSI \\
\cline { 2 - 8 } & 218.2154545 & 175.66 & 214.8262206 & 171.3377016 & 1.27221073 & 53.73881014 \\
\hline
\end{tabular}

Source: Collected from www.nseindia.com and computed

Measuring Stationarity of Stock Price during the Pre-COVID-19 Period by using Augmented Dickey Fuller Test (ADF)

The Augmented Dickey Fuller Test (ADF) is unit root test to find stationarity. Unit roots can cause unpredictable results in time series analysis. The Augmented Dickey-Fuller test can be used with serial correlation.

\section{Price Movements of FMCG Sector during the} Post COVID-19 Period

In the post-covid the RSI average is 53.73881014 . Therefore it indicates that the share is neither overbought nor oversold of FMCG.
Table 3: ADF of Pre COVID-19 in FMCG Sector

\begin{tabular}{|c|c|c|c|}
\hline \multicolumn{2}{|c|}{$\begin{array}{c}\text { Unit Root Test for FMCG } \\
\text { Index }\end{array}$} & t-Statistics & Prob.* \\
\hline $\begin{array}{c}\text { Augmented Dickey-Fuller } \\
\text { test statistics }\end{array}$ & -13.32637 & 0.0000 \\
\hline \multirow{2}{*}{$\begin{array}{c}\text { Test } \\
\text { critical } \\
\text { values }\end{array}$} & $1 \%$ level & -3.555023 & \\
\cline { 2 - 4 } & $5 \%$ level & -2.915522 & \\
\hline
\end{tabular}

Source: Collected from www.nseindia.com and computed using E-Views 7

In the augmented dickey-fuller test the t-statistics value $(-13.32637)$ is lesser than the critical value at 
all the level of significance in the price returns of FMCG index. Hence it can be interpreted that the FMCG sector index price of pre COVID-19 period has been obtained stationarity in the level itself. Further the Probability (p) value represents the rejection of hypothesis.

Measuring Stationarity of Stock Price during the Post COVID-19 Period by using Augmented Dickey Fuller Test (ADF)

Table 4: ADF of Post COVID-19 in FMCG Sector

\begin{tabular}{|c|c|c|c|}
\hline \multicolumn{2}{|c|}{$\begin{array}{c}\text { Unit Root Test for } \\
\text { FMCG Index }\end{array}$} & t-Statistics & Prob.* \\
\hline $\begin{array}{c}\text { Augmented Dickey-Fuller } \\
\text { test statistics }\end{array}$ & -16.16702 & 0.0053 \\
\hline \multirow{2}{*}{$\begin{array}{c}\text { Test critical } \\
\text { values }\end{array}$} & $1 \%$ level & -3.581152 & \\
\cline { 2 - 4 } & $10 \%$ level & -2.926622 & \\
\cline { 2 - 4 } & $10 \mathrm{y}$ lel & -2.601424 & \\
\hline
\end{tabular}

Source: Collected from www.nseindia.com and computed using E-Views 7

The result of ADF indicates that the index price of the FMCG sector has been obtained stationarity at all levels. T-Statistics value (-16.16702) is lesser than critical value in all the levels. The $\mathrm{P}$ value confirms that there is the rejection of null hypothesis.

Measuring Volatility of Stock Price during the Pre COVID-19 Period by using Generalized Autoregressive Conditional Heteroskedasticity [GARCH $(\mathbf{1 , 1 )}]$

The GARCH $(1,1)$ is the simplest and most robust of the family of volatility models. However, the model can be extended and modified in many ways. To examine the volatility level prevailing in the stock market, GARCH $(1,1)$ model has generated different values for different parameters.

Measuring Volatility of Stock Price during the Post-COVID-19 Period by using Generalized Autoregressive Conditional Heteroskedasticity [GARCH (1,1)]

The following table examines the results of the mean and variance equations of GARCH Model for the FMCG Index daily returns from January 2019 to December 2019. It is found from the analysis that the selected sample index has obtained high volatility of
$0.974456(-0.092096+1.066552)$ during the study period. That is 97 percent of volatility exist in the selected sample index during the study period. Hence the hypothesis is rejected.

Table 5: GARCH $(1,1)$ of Pre COVID-19 in FMCG Sector

\begin{tabular}{|c|c|c|c|}
\hline \multicolumn{4}{|c|}{ Mean Equation } \\
\hline Variable & Co-efficient & Std. Error & Z-Statistics \\
\hline C & 0.000258 & 0.001328 & 0.194107 \\
\hline \multicolumn{4}{|c|}{ Variance Equation } \\
\hline C & $2.47 \mathrm{E}-06$ & $3.19 \mathrm{E}-06$ & 0.773180 \\
\hline RESID(-1) & -0.092096 & 0.034765 & -2.677919 \\
\hline GARCH(-1) & 1.066552 & 0.054735 & 19.61329 \\
\hline
\end{tabular}

Source: Collected from www.nseindia.com and computed using E-Views 7

Table 6: GARCH $(1,1)$ of Post COVID-19 in FMCG Sector

\begin{tabular}{|c|c|c|c|}
\hline \multicolumn{4}{|c|}{ Mean Equation } \\
\hline Variable & Co-efficient & Std. Error & Z-Statistics \\
\hline C & -0.003263 & 0.002036 & 1.602627 \\
\hline \multicolumn{4}{|c|}{ Variance Equation } \\
\hline C & $-1.78 \mathrm{E}-05$ & $1.26 \mathrm{E}-05$ & 1.410556 \\
\hline RESID(-1) & -0.050746 & 0.095723 & -0.519685 \\
\hline GARCH(-1) & 1.227225 & 0.119600 & 10.09389 \\
\hline
\end{tabular}

Source: Collected from www.nseindia.com and computed

using E-Views 7

The result implies that the index price returns of FMCG sector after the COVID-19 obtained significant volatility of $1.176479(-0.050746+$ $1.227225)$ during the study period. That is 117 percent of volatility exist in the selected sample index during the study period. Hence the hypothesis "The Index price returns of sample indices are not volatile" is rejected and confirmed that there is significant volatility existed in FMCG industry during the study period.

\section{Conclusion}

The aim of the study is to analyse the impact of COVID-19 on stock market especially in Fast Moving Consumer Goods (FMCG) sector of National Stock Exchange. Results from Relative Strength Index(RSI) clearly shows that there is a considerable change in the market after COVID-19, the RSI increases slightly due to sudden increase 
in demand for certain products. From the result of GARCH, we can clearly understand the volatility of the FMCG sector. The result of all the analysis it can be understand that the COVID-19 in India made an adverse impact in FMCG sector. Hence from the above result there is a significant changes and impact in the FMCG sector during the study period. Being one of the vibrant sectors FMCG has to cope up with the flexible plan to overcome sudden changes in the future.

\section{References}

Agrawal, Shruti, et al. "Effect of COVID-19 on the Indian Economy and Supply Chain." Preprints, 2020.

Carlsson-Szlezak, Philipp, et al. "What Coronavirus could Mean for the Global Economy." Harvard Business Review, 2020.

"Coronavirus Impact: FMCG Firms Limit Operations Only to Essential Items, Adopt 'Work From Home" News 18 Business, 2020.

"Coronavirus Sends Food Prices Soaring in China." MarketWatch, 2020.

COVID-19 and the World of Work. International Labour Organization.

Dev, S. Mahendra, and Rajeswari Sengupta. Covid-19: Impact on the Indian Economy. Indira Gandhi Institute of Development Research, 2020.

Fernandes, Nuno. "Economic Effects of Coronavirus Outbreak (COVID-19) on the World Economy." IESE Business School Working Paper No. WP-1240-E, 2020.

Gupta, Puneet Kumar, et al. "Coronavirus2019 (COVID-19) Outbreak in India: A Perspective so far." Journal of Clinical and Experimental Investigations, vol. 11, no. 4, 2020.

Gupta, Sumit, et al. "Adoption of Sustainable Supply Operation Quality Practices and their Impact on Stakeholder's Performance and Sustainable Performance for Sustainable Competitiveness in Indian Manufacturing Companies." International Journal of Intelligent Enterprise, vol. 5, no. 1-2, 2018, pp. 108-124.
"Impact of Coronavirus on Indian Tourism could Run into Thousands of Crores of Rupees." The Economic Times, 2020.

Jakhotiya, Girish. "Impact of COVID-19 on Indian economy and the Road Ahead." MPRA Paper No. 101456, 2020.

Jamwal, Anbesh, et al. "Coronavirus Disease 2019 (COVID-19): Current Literature and Status in India." Preprints, 2020.

Kapur, Devesh, and Arvind Subramanian. "How Coronavirus Crisis can be Converted to Opportunity to Fundamentally Strengthen Indian Economy." Indian Express, 2020.

Karthik, TT, and TP Ram Prasad. "SWOT (Strength, Weakness, Opportunities and Threats) Analysis of Fast Moving Consumer Goods (FMCG) Industries in India." Shanlax International Journal of Commerce, vol. 8, no. 1, 2020, pp. 92-100.

Koshle, Himanshu, et al. Breakdown of Business and Workers in India: Impact of Coronavirus.

Mahajan, Yogesh D. "Impact of Coronavirus Pandemic on Fast Moving Consumer Goods (FMCG) Sector in India." Journal of Xi'an University of Architecture \& Technology, vol. XII, no. IX, 2020, pp. 26-31.

Mishra, Bibhuti Ranjan. "Role of External and Domestic Demand in Economic Growth: A Study of BRICS Countries." Global Business Review, vol. 21, no. 2, 2019, pp. 547-566.

Mukherjee, Writankar, and Sagar Malviya. "Coronavirus Impact: FMCG Firms Moving Fast to Restock Stores." The Economic Times, 2020.

Mukherjee, Writankar, et al. "Consumer Goods Fly off the Shelves as Coronavirus Spreads in India." The Economic Times, 2020.

Narayanan, Sudha. "Food and Agriculture during a Pandemic: Managing the Consequences." Ideas for India, 2020.

Nivetha, P and Sudhamathi, S. "Survival Strategies for Businesses during Covid-19 Lockdown." Shanlax International Journal of Management, vol. 8, no. 3, 2021, pp. 79-82.

Paris, Costas. "Coronavirus Rattles Shipping Industry as Supply Shock Moves to Demand Decline.” The Wall Street Journal, 2020. 
International Journal of Management

Patnaik, Ila, and Rajeswari Sengupta. Impact of Ray, Debraj, and S. Subramanian. "India's Covid-19 on Indian Economy: An Analysis of Lockdown: An Interim Report." NBER No. Fiscal Scenarios. Indira Gandhi Institute of Development Research, 2020.

Rajamohan, S., et al. "Impact of COVID-19 on Stock Price of NSE in Automobile Sector." International. Journal of Advanced Multidiciplinary Research, vol. 7, no. 7, 2020, pp. 24-29. 27282, 2020.

Sengupta, Rajeswari, and Harsh Vardhan. "The Pandemic and the Package." Ideas for India, 2020.

Sengupta, Rajeswari. "Covid-19: Macroeconomic Implications for India.” Ideas for India, 2020.

\section{Author Details}

Dr. S. Rajamohan, Senior Professor \& Director, Alagappa Institute of Management, Alagappa University, Karaikudi, Tamil Nadu, India, Email ID: srajamohan1988@gmail.com.

J. Jenefer, Ph.D. Research Scholar, Alagappa Institute of Management, Alagappa University, Karaikudi, Tamil Nadu, India, Email ID: Jenemilton@gmail.com.

A. Sathish, Ph.D. Research Scholar, Alagappa Institute of Management, Alagappa University, Karaikudi, Tamil Nadu, India, Email ID: astsphd@gmail.com. 